\title{
Nem tudo o que reluz é ouro: um caso de mudança curricular no Ensino Médio
}

\author{
Janete Palazzo* \\ Gabriela Sousa Rêgo Pimentel** \\ Candido Alberto Gomes***
}

\section{Resumo}

Os currículos do ensino médio brasileiro têm a tradição histórica do enciclopedismo. Apesar disso, têm recebido sucessivamente novas disciplinas segundo decisões centrais, que dependem de execução descentralizada. Uma delas foi a Língua Espanhola, por motivos geopolíticos e geoestratégicos. Este trabalho efetua um balanço preliminar da introdução da disciplina, inclusive o perfil do professor. Os resultados revelam o improviso para atender à legislação e normas, considerando a grande quantidade de docentes sem formação adequada para ministrar esta disciplina. Ademais, quase a metade dos estabelecimentos declara não oferecê-la efetivamente. Esta mudança evidencia que decisões governamentais estão sujeitas às limitações das burocracias e aos jogos políticos, o que pode resultar na sua própria deslegitimação.

Palavras-chave: Formação de professores. Políticas educacionais. Ensino médio. Língua espanhola.

\section{Introdução}

Relevantes motivos geopolíticos e geoeconômicos, ligados à participação no Mercado Comum do Sul (MERCOSUL) e às relações com os países hispanoamericanos, levaram o Brasil a incluir a Língua Espanhola no currículo do ensino médio, obrigatória para os estabelecimentos e facultativa para os alunos. A sanção da Lei $n^{\circ}$ 11.161/2005 (BRASIL, 2005), que introduziu o dispositivo na Lei de Diretrizes e Bases, já se encaminha para uma década. É conhecida

\footnotetext{
* Doutoranda em Educação da Universidade Católica de Brasília. E-mail: janjanpalazzo@yahoo.com.br

** Doutora em Educação da Universidade do Estado da Bahia1 . E-mail: meg.pimentel@uol.com.br

*** Doutor em Educação pela Universidade da Califórnia, Los Angeles. Universidade Católica de Brasília. E-mail: clgomes@terra.com.br

1 Este artigo resulta de atividades do grupo de pesquisa Formação do Professor e Currículo, integrante da linha de Políticas Públicas de Educação e Gestão de Sistemas Educacionais, da Universidade do Estado da Bahia.
} 
como "Lei do Espanhol" e "em nenhum caso pode considerar-se como um ponto de chegada, mas como um de partida para a realização de diversas políticas que permitam expandir o ensino do espanhol no Brasil" (MARTÍNEZCACHERO LASECA, 2008, p. 90). O momento merece um balanço preliminar da sua execução com os dados secundários disponíveis, a partir do personagem fundamental, além do aluno que aprende: o professor.

As poucas evidências da literatura sobre o ensino de línguas estrangeiras (GOMES et al., 2010a, 2010b) mostram que nossas escolas não são particularmente exitosas no seu ensino, haja vista a ampla e crescente presença de cursos livres no chamado sistema educacional paralelo. Pais e alunos, quando pretendem níveis mais altos de aprendizagem, precisam buscar fora da escola os meios para tanto, pagando por isso duas ou três vezes: duas, no caso da escola pública, como contribuintes de impostos e como contratantes de um curso; três, no caso da escola particular, como contribuintes e contratantes de uma escola e de um curso. Os resultados aqui apresentados advertem que currículos certamente precisam de alterações, porém estas são lentas e de altos custos, tendo consequências para o acesso e a democratização educacionais. Além disso, se os currículos mudam por adição de novos componentes, evitando alterações estruturais, tendem a alcançar mais altos níveis de complexidade e onerosidade.

Por estes e outros motivos, a inclusão de nova língua estrangeira ou outra disciplina no currículo difere de uma peça de encaixe num jogo onde existe um espaço à sua espera. Qualquer novo componente precisa inserir-se num todo, afetando esse todo e sendo por ele afetado. Cabe-lhe enriquecer a educação geral comum a todos os jovens, formando-os para a vida e a cidadania e valorizandoos como seres humanos. Em outras palavras, não se trata de ensinar mais um idioma de modo instrumental ou tecnicista.

\section{As arenas governamentais e curriculares}

As decisões governamentais, como a inclusão de um novo idioma nos currículos, podem ser vistas pelas lentes de vários paradigmas, segundo o clássico de Allison e Zelikow (1999): 1) o do ator racional, em que o governo é visto como agente unitário que faz escolhas racionais e coerentes; p. 2) o do comportamento organizacional, que concebe o governo como uma constelação 
de organizações debilmente articuladas, em cujo topo se situam os líderes governamentais. Estes têm como limites de escolha as rotinas existentes para as organizações usarem as suas capacidades, ou, em outras palavras, suas decisões podem ser cumpridas na medida em que as burocracias públicas conseguem se mover e se conjugar nas ações; 3) o paradigma político, segundo o qual os atores, localizados em diferentes posições do governo se envolvem em jogos simultâneos, hierarquicamente superpostos. As decisões e ações emergem destes jogos como resultantes políticos, isto é, consequências de compromissos, conflitos e confusão de altos funcionários, com interesses e influências desiguais.

A decisão em tela, isto é, a inclusão de uma nova disciplina, obrigatória para os estabelecimentos, se processou centralmente, para execução descentralizada, assim dependendo dos Estados, das escolas, das instituições formadoras do magistério, de órgãos de classe e outros, que podem ter diferentes prioridades e opiniões ou simplesmente podem não alcançar compreensão clara das decisões. Estes atores, ao interagirem, se afastam do paradigma racional, remetendo aos demais. Prover o ensino médio, com um currículo tão complexo, envolve grandes esforços e recursos a serem combinados, de modo a assegurar a sua concretização na ponta, para isso dispondo essencialmente de professores preparados.

Tratando-se do currículo, diferentes grupos se envolvem em competição, conflito e cooperação, numa arena política onde disputam poder ou, mais nitidamente, como uma série de arenas superpostas, conforme os níveis decisórios, tendo decisões como resultados políticos. Não sendo neutro, o currículo constitui uma seleção de conhecimentos aprovados pela sociedade e distribuídos a diversos grupos sociais em composição e dosagens diferentes. Ademais, os conhecimentos assim filtrados se estratificam em disciplinas segundo o seu prestígio, que, no caso do ensino médio, depende em parte da importância a eles atribuída pelos processos seletivos de ingresso na educação superior e, portanto, potencialmente para a mobilidade social dos jovens (YOUNG, 1971, 2010). Ao ministrarem o currículo, os atores, precisando mobilizar amplos recursos, poderão dar maior prioridade à língua nacional, à matemática e a outras disciplinas que assim alcançam mais alto status. Então, na prática o Espanhol, obrigatório para os estabelecimentos, mas facultativo para os alunos, pode situar-se no fim da fila de prioridades. Isto se agrava quando não se conta prontamente com professores e material adequados. Como resultado das limitações das burocracias e dos 
jogos políticos, pode se aplicar o "jeitinho", pelo qual se estabelece o que é "para valer"; o que não é, mas se pode dar "jeito", e o que pode ser objeto de "vista grossa", para se cumprir só em última instância.

Além da estratificação dos seus componentes, a organização do currículo repercute na seletividade sociocultural. Bernstein $(1977,1990)$ distinguiu dois códigos educacionais, isto é, princípios subjacentes que modelam o currículo, a pedagogia e a avaliação. O tipo "justaposto", com estrutura rígida e formas fechadas de classificação é mais seletivo da perspectiva sociocultural, ao contrário do tipo "integrado", com estrutura flexível e formas abertas de classificação. No caso do ensino médio, apesar das normas em favor da transversalidade e do tratamento das disciplinas por áreas, a prática indica a predominância do tipo "justaposto", com numerosos componentes relativamente isolados, cerca de 13. Com isso, o currículo se reduz à "grade horária", fragmentado conforme as estruturas tradicionais e organizado com base na relação entre turma, sala de aula, disciplina e professor horista.

Com a escola atomizada em disciplinas e turmas, falta trabalho em equipe para a integração curricular, que poderia conduzir ao tipo "integrado". Este é um modo mais fácil de gestores e professores organizarem o ensino, mas não o melhor para a aprendizagem. Além disso, o currículo tem escassa influência da escola, alunos e professores, pois o ensino médio, em sua história no Brasil, tem mantido duas constantes: 1) o caráter enciclopédico, com a frustrada intenção de abranger quase a totalidade do conhecimento; 2) o sentido propedêutico para o nível educacional seguinte, o superior, em vez dos objetivos formativos. Portanto, urge melhor entendimento da estrutura curricular do ensino médio, no intuito de minimizar a ambivalência desse nível. É preciso "reavaliar os conteúdos enciclopédicos das escolas, em virtude da heterogeneidade dos alunos e, também, mudanças culturais, tecnológicas, econômicas e sociais são requisitos para arrostar a exigência de um novo contexto de aprendizagem" (PIMENTEL, 2013, p. 103).

\section{As normas para formação de professores}

Considera-se inicialmente que, sem professor, não se pode efetuar uma alteração curricular. Por isso, cabe lembrar que a formação do professor de Espanhol no país iniciou-se com o Decreto-Lei $\mathrm{n}^{\circ}$ 1.190, de 4 de abril de 1939 (BRASIL, 
1939), que dispôs sobre a organização da Faculdade Nacional de Filosofia. Ao efetuar um diálogo com a legislação atual, três quartos de século após o Decreto-Lei, reafirma-se a necessidade de a formação do professor de língua estrangeira ser realizada na educação superior, conforme determinou a Lei de Diretrizes e Bases:

Art. 62. A formação de docentes para atuar na educação básica far-se-á em nível superior, em curso de licenciatura, de graduação plena, em universidades e institutos superiores de educação, admitida, como formação mínima para o exercício do magistério na educação infantil e nas quatro primeiras séries do ensino fundamental, a oferecida em nível médio, na modalidade Normal (BRASIL, 1996).

Vale destacar a semelhança com a formação em 1939, fixada em três anos de bacharelado, aos quais se adicionava mais um ano de disciplinas pedagógicas para o diploma de licenciatura. Este sistema, como que composto de água e azeite, valorizava um aprendizado estanque, em que a articulação entre as teorias e as práticas pedagógicas ficavam aquém do pretendido. Em outros termos, na hierarquização interna dos currículos, os conteúdos do bacharelado se consideravam mais importantes que a formação pedagógica, uma espécie de saber prático, fluido e de menor teor de cientificidade, preparando o professor segundo um código educacional "justaposto" para trabalhar na educação básica com o mesmo tipo de código. É desnecessário frisar que o modelo $3+1$ ainda persiste como sombra subjacente na formação do magistério senão como realidade concreta.

O Parecer CNE/CP n $n^{0} 5 / 2009$, que consulta sobre a licenciatura em Espanhol por complementação de estudos, tem sua resposta ratificada pelo Relator, conforme previsto no Parecer CNE/CES n 68/2008, que "não pode haver complementação de estudos para licenciados". De acordo com a Resolução CNE/CP n 2/1997 (BRASIL, 1997), esta prerrogativa é aceitável apenas para os bacharéis, que podem complementar os seus estudos. O Parecer advoga uma nova habilitação para esses profissionais, considerando o perfil formador do licenciado, vez que a carga horária para uma nova habilitação àqueles "que já possuem licenciatura em Letras, deverá ter, no mínimo, 800 (oitocentas) horas, das quais, no mínimo, 300 (trezentas) horas deverão ser dedicadas ao estágio supervisionado" (BRASIL, 2009). 
A Resolução CNE/CP n ${ }^{\circ}$ 1/2002 (BRASIL, 2002a), fundamentada nos Pareceres $\mathrm{CNE} / \mathrm{CP} \mathrm{n}^{\circ}$ 9/2001 e 27/2001, instituiu as diretrizes curriculares nacionais para formação de professores em nível superior, em cursos de licenciatura, graduação plena. A Resolução CNE/CP no 2/2002 (BRASIL, 2002b), com base no Parecer $\mathrm{CNE} / \mathrm{CP} \mathrm{n}^{\circ}$ 28/2001, estabeleceu, para esses cursos, a duração e a carga horária mínimas de três anos e de 2800 horas, das quais 400 devem ser destinadas à prática vivenciada ao longo do curso, 400 ao estágio curricular supervisionado, 1800 a conteúdo de natureza científico-cultural e 200 a outras atividades de natureza acadêmico-científico-cultural (BRASIL, 2001).

A partir dessas diretrizes gerais para os cursos de formação docente, foram estatuídas as diretrizes curriculares para cada área específica. As Diretrizes para os cursos de Letras, estabelecidas pela Resolução CNE/CES n ${ }^{\circ}$ 18/2002 (BRASIL, 2002c), fundamentada nos Pareceres CNE/CES n ${ }^{\circ} 492 / 2001$ e ${ }^{\circ}$ 1363/2001, preveem que os projetos pedagógicos dos cursos devem explicitar:

a) o perfil dos formandos nas modalidades bacharelado e licenciatura;

b) as competências gerais e habilidades específicas a serem desenvolvidas durante o período de formação;

c) os conteúdos caracterizadores básicos e os conteúdos caracterizadores de formação profissional, inclusive os conteúdos definidos para a educação básica, no caso das licenciaturas;

d) a estruturação do curso;

e) as formas de avaliação (BRASIL, 2001).

O Parecer CNE/CES no 492/2001, que propõe Diretrizes Curriculares Nacionais para os cursos de Filosofia, História, Geografia, Serviço Social, Comunicação Social, Ciências Sociais, Letras, Biblioteconomia, Arquivologia e Museologia, dispõe, para as diretrizes dos cursos de Letras (Licenciatura e Bacharelado tratados conjuntamente), que o profissional formado pelo curso de Letras, independente do grau, deve dominar o "uso da língua ou das línguas que sejam objeto de seus estudos, em termos de sua estrutura, funcionamento e manifestações culturais, além de ter consciência das variedades linguísticas e culturais" (BRASIL, 2001, p. 30).

A Resolução e os Pareceres em tela fixam as mesmas diretrizes para os graus de bacharelado e de licenciatura dos cursos de Letras, de modo que os cursos de Licenciatura devem ser orientados, ainda, pelas diretrizes supracitadas para a formação de professores. Em 2010, foram publicados os "Referenciais 
Curriculares Nacionais dos cursos de Bacharelado e Licenciatura" (BRASIL, 2010), elaborados pela Secretaria de Educação Superior (SESu), com base especialmente nas diretrizes curriculares dos mais diversos cursos de graduação, em que se apresentam, para cada curso: 1) perfil do egresso; 2) temas abordados na formação; 3) ambientes de atuação e 4) infraestrutura recomendada. Nesse documento, os referenciais são diferenciados para os graus de licenciatura e de bacharelado do curso de Letras, bem como para Língua Portuguesa e Estrangeira.

Nos referenciais específicos de Licenciatura em Letras - Língua Estrangeira, sugere-se como perfil do egresso desse curso:

...Sua atribuição central é a docência na Educação Básica, que requer sólidos conhecimentos sobre estrutura e funcionamento da Língua Estrangeira e suas literaturas, sobre seu desenvolvimento histórico e suas relações com diversas áreas; assim como sobre estratégias para transposição do conhecimento em Língua Estrangeira em saber escolar. Além de trabalhar diretamente na sala de aula, o licenciado elabora, analisa e revisa materiais didáticos, como livros, textos, vídeos, programas computacionais, ambientes virtuais de aprendizagem, entre outros. Realiza ainda pesquisas em Língua Estrangeira, coordena e supervisiona equipes de trabalho. Em suas atividades, prima pelo desenvolvimento do educando, incluindo sua formação ética, a construção de sua autonomia intelectual e de seu pensamento crítico (SESU, 2010, p. 76)

Por fim, a Resolução CNE/CP n 0 01/2011 (BRASIL, 2011) definiu diretrizes para obtenção de nova habilitação pelos portadores de diploma de Licenciatura em Letras. Esta deverá ter, no mínimo 800 horas, das quais 300 devem ser destinadas ao estágio supervisionado.

A formação e a valorização da carreira dos professores tornam-se necessidade para criar condições de um trabalho coletivo na escola que propiciem o reordenamento curricular da práxis pedagógica, em especial para que se tornem profissionais conscientes e atuantes na definição dos processos de ensinar e de avaliação das aprendizagens (OLIVEIRA, 2012). Outro ponto a destacar é a formação permanente dos docentes como condição para a melhoria da qualidade do ensino. Segundo Ruiz (2009, p. 29), “o mais relevante no processo de formação 
permanente de professores é conhecer seus resultados em termos das mudanças na sala de aula. É saber se houve alguma alteração na prática cotidiana do professor e se ela teve consequências no aprendizado dos alunos". Martínez-Cachero Laseca (2008, p. 247) alerta para o fato de que no Brasil se associa o conceito de formação continuada mais "à ideia de realizar estudos de pós-graduação do que de atualização dos conhecimentos existentes". Com isso, não há políticas públicas de formação permanente, "mas um conjunto de ações dispersas no âmbito estadual ou municipal, realizadas muitas vezes por meio de Acordos com terceiros" (p. 247).

Um estudo desenvolvido por Fernández e Rinaldi (2009) aborda a importância do ensino de Espanhol como língua estrangeira para crianças, apoiado em Piaget (1967) e Vygotsky (1993), que descrevem as etapas pelas quais as crianças transitam, bem como os postulados sobre aquisição/aprendizagem de línguas estrangeiras de Krashen (1995). Os autores enfatizam que é imprescindível suscitar uma discussão para tornar oficial a oferta de cursos de formação de professores de língua estrangeira para crianças, principalmente de Espanhol. Destacam, também, que a atual legislação brasileira não contempla a obrigatoriedade do ensino de Espanhol para a educação infantil e o ensino fundamental. Por fim, afirmam que é o momento ideal para (re)pensar a formação e qualificação docente assim como as correspondentes e necessárias alterações nos textos legais (FERNÁNDEZ; RINALDI, 2009).

\section{Quem são nossos professores de Espanhol?}

De acordo com o Censo da Educação Básica de 2012, havia 25.811 professores de Língua Espanhola no Brasil. Em termos de funções docentes ${ }^{2}$, eram 33.852, distribuídas em 21.364 estabelecimentos de ensino fundamental e médio, dos quais $45,2 \%$ vinculados à rede privada e $54,8 \%$ à rede pública de ensino. Segundo a dependência administrativa, estavam relacionadas da seguinte forma: 38,1\% nas redes estaduais; $1,0 \%$ na rede federal e $15,7 \%$ nas redes municipais. Quanto à localização, 87,3\% eram urbanas. Por Região Geográfica, 33,4\% das escolas que ofereciam espanhol estavam no Sudeste; $24,7 \%$ no Nordeste; $19,8 \%$ no Sul; $11,4 \%$ no Norte e $10,6 \%$ no Centro-Oeste.

2 "A definição de função docente admite que um mesmo professor possa ser contado mais de uma vez no exercício de suas atribuições como regente de classe, na medida em que a produção da informação estatística focalize cortes ou estratos específicos, tais como turmas, etapas e modalidades de ensino, dependência administrativa da escola (federal, estadual, municipal ou privada), unidade da federação, etc. Para cada um desses conjuntos, os resultados censitários identificam a duplicidade de contagem de docentes ocorrida em cada nível de agregação analisado (etapa ou modalidade de ensino, dependência administrativa, localização, turno, escola, turma ou disciplina)." (INEP, 2009, p. 18). 
Ressalta-se, ainda, que apenas cerca da metade, isto é, $13.740(50,6 \%)$ das escolas brasileiras de ensino médio ofereciam o idioma, ainda que obrigatório para os estabelecimentos. Por Região Geográfica, conforme demonstrado na Tabela 1, o Centro-Oeste é o que tem maior proporção de estabelecimentos em conformidade com o estabelecido pela Lei. O estudo de Martínez-Cachero Laseca (2008, p. 236) já revelava que a presença do Espanhol no sistema educacional brasileiro era muito desigual, visto que, em 2008, havia "Estados onde quase se pode dizer que se cumpre a Lei ou que, ao menos, parece previsível que possa vir a cumprir; outros Estados adotaram medidas com certa indiferença (...), outros (...) não fizeram praticamente nada".

Tabela 1 - Brasil - Total de estabelecimentos de ensino médio e estabelecimentos que oferecem Língua Espanhola, 2012

\begin{tabular}{l|l|l|l}
\hline $\begin{array}{l}\text { Região } \\
\text { Geográfica }\end{array}$ & $\begin{array}{l}\text { Total de } \\
\text { estabelecimentos (A) }\end{array}$ & $\begin{array}{l}\text { No de estabelecimentos que } \\
\text { oferecem Língua Espanhola (B) }\end{array}$ & \% (B/A) \\
\hline Norte & 2.041 & 975 & 47,8 \\
Nordeste & 6.875 & 3.540 & 51,5 \\
Sudeste & 11.853 & 4.890 & 41,3 \\
Sul & 4.306 & 2.777 & 64,5 \\
Centro-Oeste & 2.089 & 1.558 & 74,6 \\
Brasil & 27.164 & 13.740 & 50,6 \\
\hline
\end{tabular}

Fonte: INEP (2013).

Nota: Apesar de a legislação determinar aos estabelecimentos de ensino médio a obrigatoriedade da Língua Espanhola, numerosas escolas de ensino fundamental declararam ao Censo oferecê-la.

De acordo com o mesmo Censo, entre as funções docentes de Língua Espanhola na educação básica brasileira, 21,4\% eram desempenhadas por homens e 78,6\% por mulheres. Confirma-se uma profissão predominantemente feminina, que reflete sua relativa desvalorização quando os salários passaram a reduzir-se (ALMEIDA, 1996, 1998; GOUVEIA, 1970; LOURO, 2011). O Gráfico 1 apresenta a distribuição das funções docentes por sexo, segundo a Região Geográfica. Comparados estes dados ao total nacional, nota-se certa semelhança na representação dos gêneros na disciplina de Língua Espanhola. O percentual de homens no magistério da educação básica era de $19,6 \%$ no ano de 2012 . A Região Norte era a que apresentava maior proporção na educação básica: $28,8 \%$ eram professores. 
Gráfico 1 - Brasil - Funções docentes de Língua Espanhola na Educação Básica por sexo segundo as Regiões Geográficas, 2012

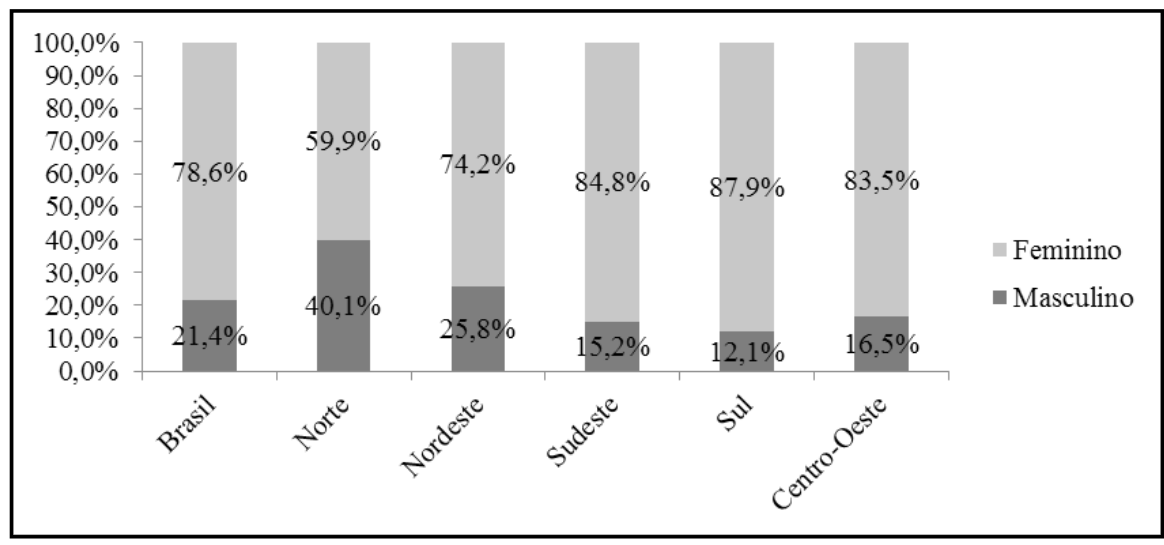

Fonte: INEP (2013).

Verifica-se na Região Norte uma distribuição relativamente próxima de mulheres $(59,9 \%)$ e homens $(40,1 \%)$ lecionando Espanhol. No Nordeste, são $25,8 \%$ de homens e $74,2 \%$ de mulheres. No Sudeste, $15,2 \%$ de homens e $84,8 \%$ de mulheres. No Sul, $12,1 \%$ de homens e $87,9 \%$ de mulheres e, por fim, na Região CentroOeste, $16,5 \%$ de homens e $83,5 \%$ de mulheres. Aparentemente as Regiões de menor desenvolvimento relativo apresentam maior participação masculina, talvez porque o magistério seja mais vantajoso no leque de oportunidades ocupacionais.

Por Unidade da Federação, verifica-se que o Amazonas possui uma concentração superior de homens $(57,8 \%)$ em relação às mulheres $(42,2 \%)$, especialmente quando comparada aos dados nacionais, demonstrando que, neste Estado, a profissão está atraindo homens. Por outro lado, o Rio Grande do Sul é o Estado que dispõe de mais mulheres $(90,1 \%)$ lecionando esta disciplina.

\section{Faixa etária e cor da pele dos professores}

Quanto à faixa etária dos professores de Espanhol, 62,0\% concentram-se entre 25 e 32 anos $(30,9 \%)$ e entre 33 e 40 anos $(30,7 \%)$. A média de idade foi de 36,92 , a mediana, de 35 anos, e a moda, de 31 . O desvio padrão mostra uma variação em torno da média de 9,291 anos, isto é, entre 27,629 a 46,211 anos. O grupo, de fato, é heterogêneo, com valores mínimo e máximo de idade, respectivamente, de 14 e 92 anos. 
Desagregados regionalmente, os dados mostram que a Região Nordeste é a que mais concentra jovens na faixa etária de até 24 anos $(8,7 \%)$, seguida da Região Norte (7,3\%). Na Região Sul, apenas 5,1\% dos professores estão nesta faixa. No Sudeste, são 5,4\% e no Centro-Oeste, 6,3\%. Esta é uma informação preocupante, pois revela que a profissão docente está atraindo poucos jovens, como já concluído por vários estudos (GATTI, 2009; OCDE, 2006; TARTUCE; NUNES; ALMEIDA, 2010).

Quando estes dados são cotejados com os do total de docentes da educação básica, constatam-se resultados similares. No país, 28,4\% dos ocupantes de funções docentes têm até 32 anos. Este percentual eleva-se para 31,3\% na Região Nordeste. No Sudeste, $25,6 \%$ encontram-se nessa faixa etária. Por outro lado, 43,5\% têm acima de 41 anos. O percentual de funções docentes com mais de 41 anos concentra-se nas Regiões Sudeste $(47,9 \%)$ e Sul $(44,8 \%)$, onde o desenvolvimento econômico relativo é maior.

Por Estado, pode-se afirmar que os que mais atraem jovens para lecionar Espanhol são Paraíba (13,2\%), Ceará (10,9\%), Alagoas (10,4\%), Acre (9,9\%) e Pernambuco $(9,2 \%)$. Já os que menos atraem jovens são: Amapá $(3,2 \%)$, Rio Grande do Sul (3,5\%), Minas Gerais (4,3\%), Rio de Janeiro (4,5\%) e Rondônia (4,5\%).

Quando analisada a quantidade de docentes com 50 anos ou mais, verifica-se que $12,9 \%$ dos docentes do Amapá e o mesmo percentual no Rio Grande do Sul estão nessa faixa etária, vindo a seguir o Rio Grande do Norte (12,2\%), Rondônia (11,3\%), Rio de Janeiro (11,2\%) e Minas Gerais (11,0\%), revelando, assim, a proximidade que estes docentes estão da aposentadoria. Os Estados com menor representação de docentes nessa faixa etária são: Piauí $(4,1 \%)$, Acre (4,7\%), Mato Grosso do Sul (5,9\%), Distrito Federal (6,0\%) e Paraíba (6,0\%).

Em relação à cor da pele dos professores, a maioria dos ocupantes de funções docentes, $42,1 \%$, se declara branca; pardos, $22,5 \%$, e não declaram sua cor, $31,2 \%$ (Tabela 2). Apesar da relativa seletividade socioeconômica da educação superior, o perfil não está distante do traçado pela PNAD-2012 para a população residente total, que inclui $46,2 \%$ de brancos, $45,0 \%$ de pardos e $7,9 \%$ de pretos, sendo de $0 \%$ os não declarantes (IBGE, 2013). Os dados referentes às funções docentes de Língua Espanhola mais uma vez se aproximam do perfil dos docentes da educação básica no Brasil. 
Tabela 2 - Brasil - Funções docentes da educação básica e de Língua Espanhola segundo a declaração da cor da pele, 2012

\begin{tabular}{l|l|l|l|l}
\hline & \multicolumn{2}{|l|}{$\begin{array}{l}\text { Funções Docentes } \\
\text { da Educação Básica }\end{array}$} & \multicolumn{2}{l}{$\begin{array}{l}\text { Funções Docentes } \\
\text { de Língua Espanhola }\end{array}$} \\
\hline Cor/ raça & Frequência & Percentual & Frequência & Percentual \\
\hline Amarela & 12.389 & 0,6 & 147 & 0,4 \\
Branca & 886.694 & 42,2 & 14.244 & 42,1 \\
Indígena & 9.482 & 0,5 & 357 & 1,1 \\
Não declarado & 623.287 & 29,7 & 10.552 & 31,2 \\
Parda & 490.164 & 23,3 & 7.633 & 22,5 \\
Preta & 79.392 & 3,8 & 919 & 2,7 \\
Total & 2.101 .408 & 100,0 & 33.852 & 100,0 \\
\hline
\end{tabular}

Fonte: INEP (2013).

\section{Formação dos professores de Língua Espanhola}

Das funções docentes de Língua Espanhola no país, 12,8\% dos seus ocupantes não possuem curso superior, $6,3 \%$ estão cursando e $80,9 \%$ já concluíram seus cursos. Entre os que terminaram seus estudos de nível superior, $92,1 \%$ são graduados em cursos da área de Educação, mas 90,2\% têm curso de licenciatura. A Tabela 3 revela a área geral da formação desses ocupantes de funções docentes.

Tabela 3 - Brasil - Formação dos ocupantes de funções docentes de Espanhol que têm curso superior, 2012

\begin{tabular}{l|l|l}
\hline Área Geral & Frequência & Percentual \\
\hline Agricultura e veterinária & 24 & 0,1 \\
Ciências Sociais, negócios e direito & 411 & 1,6 \\
Ciências, matemática e computação & 91 & 0,3 \\
Educação & 24.264 & 92,1 \\
Engenharia, produção e construção & 47 & 0,2 \\
Humanidades e artes & 1.330 & 5,1 \\
Saúde e bem estar social & 93 & 0,4 \\
Serviços & 73 & 0,3 \\
Não informados & 1.040 & \\
Total & 27.373 & 100,0 \\
\hline
\end{tabular}

Fonte: INEP (2013).

A Tabela 3 revela que a maioria dos ocupantes das funções docentes $(92,1 \%)$ tem formação na área de Educação. Em seguida, aparecem os formados em 
Humanidades e artes (5,1\%). Os demais (2,8\%) têm formações diversas. A falta de formação em Educação pode sugerir atividades complementares no magistério e/ou desvio ocupacional. De fato, a docência, muitas vezes, é percebida como "um campo profissional que tem espaço para absorver os seus profissionais, campo que estaria de 'portas abertas', mesmo em época de crise econômica, com altas taxas de desemprego, constituindo-se em 'reduto de empregos" (MIRANDA, 2011, p. 75). Ao mesmo tempo, a profissão é vista como "bico" ou "compasso de espera", escolhida até que surjam melhores oportunidades (BUENO; ENGE, 2004).

Dos professores formados na área geral de Educação, segundo classificação de cursos pela OCDE, 30,5\% estão agrupados em "Formação de professor de língua/literatura vernácula e língua estrangeira moderna"; 25,2\% no grupo de "formação de professor de língua/literatura vernácula (português)"; 22,5\% no grupo de "formação de professor de língua/literatura estrangeira moderna" e 10,9\% são graduados em "Pedagogia". Desagregando os dados, a Tabela 3 apresenta a formação dos ocupantes de funções docentes de Espanhol na área geral de Educação, segundo a classificação de cursos da OCDE.

Tabela 3 - Brasil - Área específica da formação dos ocupantes de funções docentes de Espanhol graduados na área geral de Educação, segundo a classificação de cursos da OCDE, 2012

\begin{tabular}{l|l|l}
\hline Área da formação & Frequência & Percentual \\
\hline Administração educacional & 6 & 0,0 \\
Ciência da educação & 448 & 1,8 \\
Formação de professor de artes (educação artística) & 5 & 0,0 \\
Formação de professor de artes visuais & 27 & 0,1 \\
Formação de professor de biologia & 323 & 1,3 \\
Formação de professor de ciências & 109 & 0,4 \\
Formação de professor de ciências humanas & 1 & 0,0 \\
Formação de professor de computação (informática) & 6 & 0,0 \\
Formação de professor de disciplinas do setor primário (agricul- & 2 & 0,0 \\
tura, pecuária, etc.) & 155 & 0,6 \\
Formação de professor de educação física & 2 & 0,0 \\
Formação de professor de educação religiosa & 167 & 0,7 \\
\hline Formação de professor de filosofia &
\end{tabular}




\begin{tabular}{|c|c|c|}
\hline Formação de professor de física & 30 & 0,1 \\
\hline Formação de professor de geografia & 358 & 1,5 \\
\hline Formação de professor de história & 483 & 2,0 \\
\hline Formação de professor de língua/literatura estrangeira moderna & 5.462 & 22,5 \\
\hline $\begin{array}{l}\text { Formação de professor de língua/literatura vernácula (portu- } \\
\text { guês) }\end{array}$ & 6.108 & 25,2 \\
\hline $\begin{array}{l}\text { Formação de professor de língua/literatura vernácula e língua } \\
\text { estrangeira moderna }\end{array}$ & 7.411 & 30,5 \\
\hline Formação de professor de matemática & 307 & 1,3 \\
\hline Formação de professor de música & 14 & 0,1 \\
\hline Formação de professor de química & 62 & 0,3 \\
\hline Formação de professor de sociologia & 76 & 0,3 \\
\hline Formação de professor de teatro (artes cênicas) & 2 & 0,0 \\
\hline Licenciatura Intercultural Indígena & 7 & 0,0 \\
\hline Licenciatura para a educação profissional e tecnológica & 54 & 0,2 \\
\hline Pedagogia & 2.639 & 10,9 \\
\hline Total & 24.264 & 100,0 \\
\hline
\end{tabular}

Fonte: INEP (2013).

Os dados censitários não permitem identificar quantos ocupantes de funções docentes têm formação específica em espanhol, de modo que eles se incluem entre os que declaram curso de língua/literatura estrangeira moderna e língua/literatura vernácula e língua estrangeira moderna. No entanto, é preciso considerar que, entre estes, se encontram os docentes de inglês, francês e outras línguas. Assim, no máximo 53,0\% dos professores de Espanhol com licenciatura teriam formação específica, numa hipótese altamente otimista. Como o inglês tem uma longa tradição de ensino, é possível que a maioria tenha habilitação neste idioma. Em outras palavras, é provável que o número de professores sem formação, lecionando espanhol seja inferior à metade do total.

Este componente curricular não constituiria exceção, visto que estudo exploratório sobre o professor brasileiro, com base nos dados do Censo Escolar de 2007 (INEP, 2009), revelou, por exemplo, que as disciplinas Biologia, Matemática, Química e Física estavam sendo ministradas por professores de 
áreas diferentes daquelas da sua formação específica. No caso da Física, o mais crítico deles, apenas 39,4\% dos docentes do ensino médio tinham formação na área. Para a disciplina Química, a proporção era de 55,6\%. Para os anos finais do ensino fundamental, a situação era semelhante. Havia 38,3\% de professores de Matemática graduados em áreas diversas desta.

Ademais, diferentemente da habilitação que recebem para atuar na educação infantil e nos anos iniciais do ensino fundamental, havia, no Brasil, pedagogos responsáveis por lecionar nos anos finais do ensino fundamental na proporção de $17,0 \%$ para a disciplina Língua Portuguesa; 16,9\% para Matemática; 18,9\% para Ciências; $18,7 \%$ para História; $18,9 \%$, Geografia e 24,1\% para Artes (INEP, 2009). Ou seja, apesar de não terem formação para ministrar essas disciplinas, ainda assim estavam em sala de aula, demonstrando os improvisos "necessários" para a continuidade do funcionamento das escolas. Mantendo currículos sobrecarregados, forma-se um bricabraque na formação dos docentes em exercício.

Passando aos profissionais não formados em licenciatura, a Tabela 4 apresenta o amplo leque de áreas de que eles provêm. Neste quadro de precariedade, constata-se que, apenas $43,2 \%$ deles têm complementação pedagógica, mas dificilmente esta teria especificidade para o ensino de línguas. Cabe lembrar que os programas de formação pedagógica foram criados especialmente para bacharéis já atuantes no magistério.

Tabela 4 - Brasil - Área de formação dos ocupantes de funções docentes de Espanhol no país sem licenciatura, por área específica, 2012

\begin{tabular}{l|l|l}
\hline Área & Frequência & Percentual \\
\hline Agricultura, florestas e recursos pesqueiros & 19 & 0,8 \\
Arquitetura e construção & 10 & 0,4 \\
Artes & 92 & 3,6 \\
Ciências & 22 & 0,9 \\
Ciências físicas & 32 & 1,3 \\
Ciências sociais e comportamentais & 92 & 3,6 \\
Comércio e administração & 174 & 6,9 \\
Computação & 21 & 0,8 \\
Direito & 104 & 4,1 \\
\hline
\end{tabular}

(continua) 


\begin{tabular}{l|l|l}
\hline Engenharia e profissões correlatas & 29 & 1,1 \\
Formação de professor e ciências da educação & 454 & 18,0 \\
Humanidades e letras & 1.238 & 49,1 \\
Jornalismo e informação & 41 & 1,6 \\
Matemática e estatística & 15 & 0,6 \\
Produção e processamento & 8 & 0,3 \\
Proteção ambiental & 1 & 0,0 \\
Saúde & 85 & 3,4 \\
Serviço social & 8 & 0,3 \\
Serviços pessoais & 72 & 2,9 \\
Veterinária & 5 & 0,2 \\
Não informados & 164 & \\
Total & 2.686 & 100,0 \\
\hline
\end{tabular}

Fonte: INEP (2013).

Pela classificação de cursos da $\mathrm{OCDE}$, entre as funções docentes que não têm licenciatura, observou-se que 30,1\% têm o curso de "Língua/literatura vernácula e línguas/literaturas estrangeiras modernas" e 11,5\% o curso de "Línguas/literaturas estrangeiras modernas". Ora, esses docentes apresentam conhecimento da disciplina, mas não têm a formação pedagógica que os cursos de formação de professores oferecem.

Por outro lado, há que considerar os professores que estão cursando nível superior. Das 2137 funções docentes nessa situação, 93,6\% declararam estar matriculados em cursos da área de Educação, de modo que 92,3\% são cursos para formação de professores. A distribuição das áreas gerais de tais cursos é apresentada na Tabela 5. De acordo com Imbernón (2009, p. 46), a formação docente deve proporcionar aspectos voltados à reflexão sobre a educação e a realidade social por meio de experiências diversificadas, possibilitando aos docentes os subsídios necessários para atuar como "verdadeiros agentes sociais, capazes de planejar e gerir o ensino-aprendizagem, além de intervir nos complexos sistemas que constituem a estrutura social e profissional". 
Tabela 5 - Brasil - Áreas gerais dos cursos em que estão matriculados os ocupantes de funções docentes de Espanhol que estão cursando nível superior, 2012

\begin{tabular}{l|l|l}
\hline Área & Frequência & Percentual \\
Agricultura e veterinária & 2 & 0,1 \\
Ciências sociais, negócios e direito & 33 & 1,6 \\
Ciências, matemática e computação & 6 & 0,3 \\
Educação & 1.946 & 93,6 \\
Engenharia, produção e construção & 2 & 0,1 \\
Humanidades e artes & 82 & 3,9 \\
Saúde e bem estar social & 4 & 0,2 \\
Serviços & 5 & 0,2 \\
Não informados & 57 & 100,0 \\
Total & 2.137 &
\end{tabular}

Fonte: INEP (2013).

Em síntese, a formação dos ocupantes de funções docentes de Espanhol atuantes na Educação Básica se apresenta conforme a Figura 1.

Figura 1 - Brasil - Síntese da distribuição percentual das funções docentes de Espanhol atuantes na Educação Básica por categoria da formação, 2012

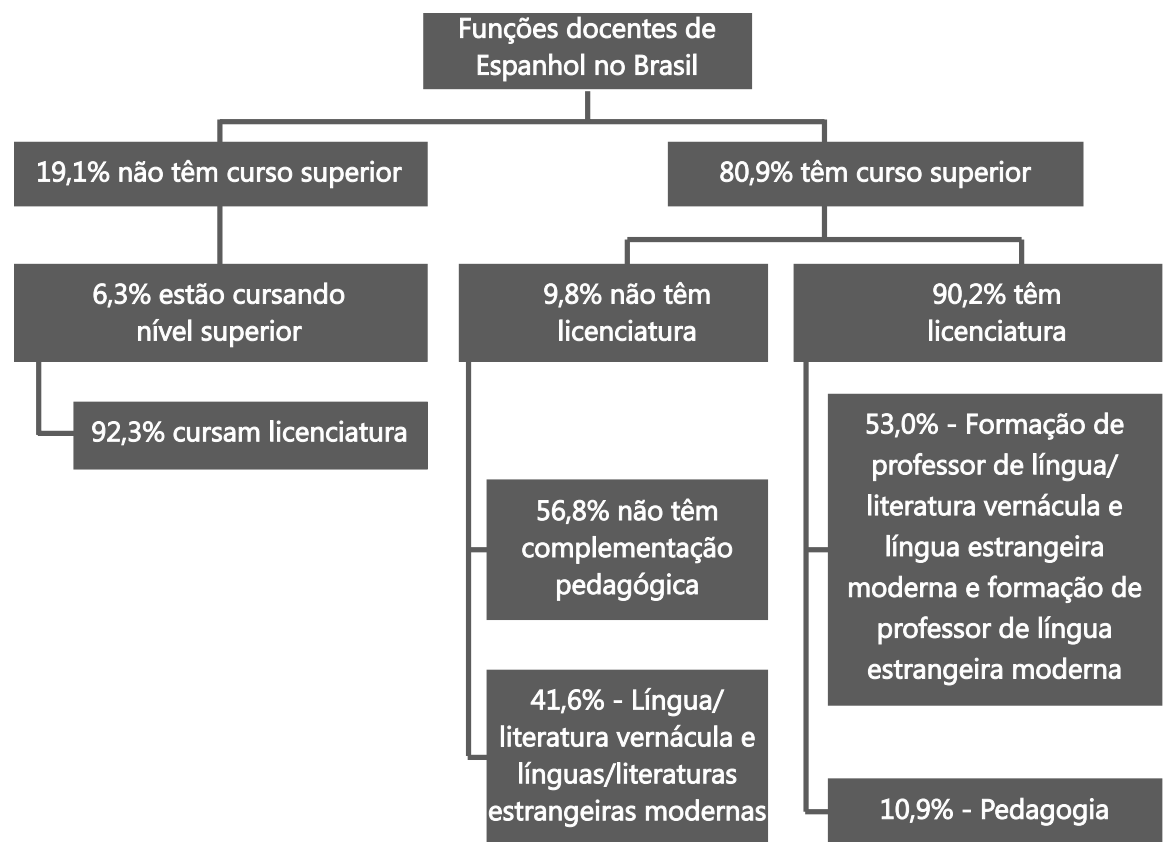




\section{Muitos alunos, poucos professores}

Em 2012, havia, no Brasil, um total de 50.545.050 matrículas na educação básica, incluídas todas as etapas e modalidades, para 2.101 .408 funções docentes, gerando uma razão simples de 24 matrículas por função docente. Segundo Sampaio e Marin (2004), a média dessa razão para os países da OCDE, em 2004, era de 17 para a educação primária, 15 para as séries iniciais do ensino secundário e 14 para as séries finais.

A partir de dados do Censo da Educação Básica de 2012, foi calculada esta proporção para a matrícula no ensino médio por função docente de Língua Espanhola. Como demonstrado na Tabela 6, o Brasil tinha 8.376.852 matrículas no ensino médio e apenas 21.143 funções docentes para lecionar esta disciplina neste nível de ensino, cuja oferta pelas escolas é obrigatória. A relação entre as matrículas e as funções docentes no país era de 396, o que sugere necessidade imediata de aumento da quantidade de professores deste componente curricular em todas as Regiões do país, já que um número acanhado de funções docentes provavelmente limita a oferta deste componente curricular. Em outras palavras, o nível de implantação da Lei é ainda muito modesto.

Tabela 6 - Brasil - Matrícula total, funções docentes relativas ao espanhol e relação média matrículas/função docente no Ensino Médio, por Região Geográfica, 2012

\begin{tabular}{l|l|l|l}
\hline Região Geográfica & $\begin{array}{l}\text { Matrícula } \\
\text { Total (A) }\end{array}$ & $\begin{array}{l}\text { Funções Docentes } \\
\text { de Espanhol (B) }\end{array}$ & $\begin{array}{l}\text { Relação média matrículas/ } \\
\text { funão docente (A/B) }\end{array}$ \\
\hline Brasil & 8.376 .852 & 21.143 & 396 \\
Norte & 772.578 & 1.958 & 395 \\
Nordeste & 2.354 .227 & 6.115 & 385 \\
Sudeste & 3.474 .504 & 6.466 & 537 \\
Sul & 1.141 .452 & 3.880 & 294 \\
Centro-Oeste & 634.091 & 2.724 & 233 \\
\hline
\end{tabular}

Fonte: INEP (2013).

Uma função docente para cada 396 alunos é uma relação extremamente alta, depreendendo-se que as escolas não cumprem a obrigatoriedade, tanto que apenas 50,6\% delas, no ensino médio, declararam oferecer a disciplina. Em outras palavras, a Língua pode integrar formalmente a grade curricular, mas em muitos 
casos não seria oferecida. No caso de efetiva oferta, os números sugerem modesta qualidade do processo de ensino e de aprendizagem, além de prejuízos à saúde do professor, que teria alta sobrecarga de trabalho. Ademais, é uma proporção muito distante das obtidas pelos países desenvolvidos e também da média brasileira para todas as disciplinas, que, em 2012, foi de 17 matrículas por função docente. Ao mesmo tempo, verifica-se a grande proporção de funções docentes no país que lecionam para nove turmas ou mais $(21,2 \%)$, ou seja, uma em cada cinco funções docentes do ensino médio ministram aulas para mais de oito turmas.

Pela análise da Tabela 6, verifica-se que a Região Sudeste apresenta uma relação ainda maior: 537 alunos por função docente. Por outro lado, a Região CentroOeste é a que tem a menor proporção: 233 matrículas por função docente, o que ainda é um número preocupante.

Deve-se considerar, igualmente, que, quando um professor leciona em mais de uma escola ou em mais de um nível, ele exerce uma função docente em cada unidade escolar, consequentemente, o mesmo professor pode ser contabilizado mais de uma vez no Censo. Ou seja, a razão real entre a quantidade de matrículas e as funções docentes pode ser ainda mais alta. Ressalta-se, ainda, que, quanto maiores a dedicação e a disponibilidade do professor, melhor o desempenho dos alunos (SOARES, 2003).

Outro ponto a sublinhar é a associação desses indicadores às condições operacionais do ambiente escolar. De acordo com a pesquisa $O$ que Pensam os Jovens de Baixa Renda sobre a Escola (BRASIL, 2013), realizada em São Paulo e Recife com jovens entre 15 e 19 anos, o absenteísmo dos professores chega a $42 \%$. Esta falha, bem como as aulas sem atividades práticas, foram observações negativas relacionadas, em algumas situações, ao abandono escolar. Ora, quanto maior a quantidade de alunos por professor, maior será sua dificuldade em preparar aulas criativas e em dar atenção mais personalizada aos estudantes, identificando seus progressos e dificuldades, de modo que possam dominar um idioma estrangeiro. Tais condições certamente explicam tantos cursos de línguas, no sistema educacional paralelo, como antes aludido.

Quando desmembrados os dados por dependência administrativa, observa-se que a rede privada tem uma relação bem inferior (121 matrículas por função docente) à da rede pública (547 matrículas por função docente). A Tabela 7 apresenta detalhadamente a proporção identificada. 
Tabela 7 - Brasil - Matrícula total, funções docentes relativas ao Espanhol e relação média matrículas/função docente no Ensino Médio, por dependência administrativa, 2012

\begin{tabular}{lllll}
\hline $\begin{array}{l}\text { Dependência } \\
\text { administrativa }\end{array}$ & $\begin{array}{l}\text { Matrícula } \\
\text { Total (A) }\end{array}$ & Funções Docentes (B) & $\begin{array}{l}\text { Relação média matrículas/ } \\
\text { funçõo docente (A/B) }\end{array}$ \\
\hline Federal & 126.723 & 299 & 424 \\
Estadual & 7.111 .741 & 11.870 & 599 \\
Municipal & 72.225 & 194 & 372 \\
Total Pública & 7.310 .689 & 13.363 & 547 \\
Total Privada & 1.066 .163 & 8.780 & 121 \\
TOTAL & 8.376 .852 & 21.143 & 396 \\
\hline
\end{tabular}

Fonte: INEP (2013).

\section{Levantando a ponta do véu}

O caso da Língua Espanhola é como levantar uma ponta do véu que encobre a realidade do ensino médio. Currículos extensos, diversificados, compartimentados e relativamente padronizados, seguindo o código "justaposto", têm altos custos e tendem a ser mais seletivos do ponto de vista sociocultural, isto é, são obstáculos à democratização educacional. Dificultam a relação entre educação e vida, concorrendo para o aborrecimento dos alunos na escola, o menor aproveitamento e o abandono. Na dificuldade de integralizar as chamadas grades horárias, redes escolares e estabelecimentos buscam professores sem formação específica para assumir cargas horárias semanais relativamente reduzidas. Em outras palavras, a complexidade e o alto custo dos currículos levam à improvisação, não só no caso da Língua Espanhola, mas também em outros componentes curriculares.

A introdução do Espanhol por acréscimo ao currículo é, portanto, parte de uma problemática maior, que patenteia: 1) o reforço ao código educacional "justaposto", que contribui para o fracasso escolar; 2) o aumento da complexidade curricular à medida que, por aposição, chegam novos componentes; 3 ) os altos custos de alterações curriculares nacionais e a dispersão dos recursos por múltiplas frentes; 4) as dificuldades maiores da gestão curricular, escolar e 
educacional, que concorrem para aqueles altos custos; 5) o usual ritmo lento da formação de professores, que recomenda a implantação progressiva de alterações; 6) a improvisação de profissionais que, embora com uma formação especializada por disciplina, são convidados, na prática, a serem polivalentes (é interessante recordar que a polivalência, quando instituída, foi rejeitada); 7) novamente a necessidade de rever a formação de professores, tendente a ser cada vez mais especializada e seguidora de uma tradição histórica que inferioriza o preparo pedagógico em face do conteúdo.

É claro que, se o professor aprende, na sua formação, que o conteúdo é superior à pedagogia, tende-se a manter um ensino conteudista, calcado na mera transmissão de conhecimentos. Desse modo, uma mudança bem intencionada de interesse geopolítico e geoeconômico para o país, como é a adição da Língua Espanhola ao currículo do ensino médio, carrega consigo um cortejo de consequências que leva a considerar a frustração de pelo menos parte considerável do resultado final desejado, isto é, certo domínio pelos alunos da língua dos outros países integrantes do Mercosul, uma das mais faladas e publicadas no mundo.

O peso das burocracias públicas e sua dispersão, bem como os jogos políticos dos atores que buscam acomodar as novas leis e normas, mostra uma vez mais que as decisões dos governos não se limitam a escolhas racionais. No ápice da pirâmide, motivações políticas de amplo alcance levam a decidir, neste caso, um acréscimo curricular. Porém, ao descer para outros andares da pirâmide, as diferentes engrenagens burocráticas e políticas estabelecem uma hierarquização de prioridades de execução. O "jeitinho" estende um manto de sombra que oculta o não cumprimento pleno da decisão central. Esta "digestão" reiterada das decisões pelas engrenagens acaba por deslegitimar leis e normas: são elas "para valer"? Mais uma vez pode-se constatar o hiato entre os valores proclamados e os valores reais nas instituições escolares brasileiras (TEIXEIRA, 1962). Por múltiplos fatores, decisões do centro sofrem graves distorções no seu trajeto até à sala de aula. Portanto, decisões não são atos singulares de vontade racional, mas processos cuja complexidade precisa ser antevista e prevista para que se encarnem na prática e não criem novos precedentes do seu cumprimento apenas ritual. 


\section{Referências}

ALLISON, G.; ZELIKOW, P. Essence of decision. 2. ed. Nova Iorque: Longman, 1999.

ALMEIDA, J. Mulheres na escola: algumas reflexões sobre o magistério feminino. Cadernos de Pesquisa, São Paulo, n. 96, p. 71-78, fev. 1996.

. Mulher e Educação: a paixão pelo possível. São Paulo: UNESP, 1998.

BERNSTEIN, B. Class, codes and control. Londres: Routledge and Kegan Paul, 1977. (v. 3; Towards a theory of educational transmissions).

. Class, codes and control. Londres: Routledge and Kegan Paul, 1990. (v. 4; The structuring of pedagogic discourse).

BRASIL. Decreto-Lei no 1.190 , de 4 de abril de 1939. Dá organização à Faculdade Nacional de Filosofia. Diário Oficial da União, Brasília, DF, 6 abr. 1939. Seção 1. Disponível em: <http://www2.camara.leg.br/legin/fed/declei/1930-1939/decreto-lei1190-4-abril-1939-349241-publicacaooriginal-1-pe.html>. Acesso em: 14 ago. 2013.

. Lei $\mathrm{n}^{\circ}$ 9.394, de 20 de dezembro de 1996. Estabelece as diretrizes e bases da educação nacional. Diário Oficial da União, Brasília, DF, 23 dez. 1996. Disponível em: <http://www.planalto.gov.br/ccivil_03/LEIS/19394.htm>. Acesso em: 02 ago. 2013.

. Lei $\mathrm{n}^{\circ} 11.161$, de 5 de agosto de 2005. Dispõe sobre o ensino da língua espanhola. Diário Oficial da União, Brasília, DF, 8 ago. 2005. Disponível em: <http://www.planalto.gov.br/ccivil_03/_Ato2004-2006/2005/Lei/L11161. htm>. Acesso em: 02 ago. 2013.

. Ministério da Educação. Conselho Nacional de Educação. Resolução $\mathrm{CNE} / \mathrm{CP} \mathrm{n}^{\circ} 2$, de 26 de junho de 1997. Dispõe sobre os programas especiais de formação pedagógica de docentes para as disciplinas do currículo do ensino fundamental, do ensino médio e da educação profissional em nível médio. Disponível em: <http://portal.mec.gov.br/cne/arquivos/pdf/rcp002_97.pdf>. Acesso em: 08 jul. 2013. 
BRASIL. Resolução CNE/CP $n^{\circ} 1$, de 18 de fevereiro de 2002. Institui Diretrizes Curriculares Nacionais para a Formação de Professores da Educação Básica, em nível superior, curso de licenciatura, de graduação plena. Diário Oficial da União, Brasília, DF, 9 abr. 2002a. Seção 1, p. 31. Disponível em: <http://portal.mec.gov.br/cne/arquivos/pdf/rcp01_02.pdf>. Acesso em: 08 jul. 2013.

. Resolução $\mathrm{CNE} / \mathrm{CP} \mathrm{n}^{\circ}$ 2, de 19 de fevereiro de 2002. Institui a duração e a carga horária dos cursos de licenciatura, de graduação plena, de formação de professores da Educação Básica em nível superior. Diário Oficial da União, Brasília, DF, 4 mar. 2002b. Seção 1, p. 9. Disponível em: <http://portal.mec. gov.br/cne/arquivos/pdf/CP022002.pdf $>$. Acesso em: 08 jul. 2013.

. Resolução CNE/CES n ${ }^{\circ}$ 18, de 13 de março de 2002. Estabelece as Diretrizes Curriculares para os cursos de Letras. Diário Oficial da União, Brasília, DF, 9 abr. 2002c. Seção 1, p. 34. Disponível em: <http://portal.mec. gov.br/cne/arquivos/pdf/CES182002.pdf>. Acesso em: 08 jul. 2013.

. Resolução CNE/CP no 01, de 18 de março de 2011. Estabelece diretrizes para a obtenção de uma nova habilitação pelos portadores de Diploma de Licenciatura em Letras. Diário Oficial da União, Brasília, DF, 22 mar. 2011. Seção 1, p. 14-15. Disponível em: <http://portal.mec.gov.br/ index.php?option $=$ com_docman\&task $=$ doc_download\&gid $=7711 \&$ Itemid $=>$. Acesso em: 08 jul. 2013.

. Parecer $\mathrm{CNE} / \mathrm{CP} \mathrm{n}^{\circ} 27$, de 2 de outubro de 2001. Dá nova redação ao parecer CNE/CP 9/2001, que dispõe sobre as Diretrizes Curriculares Nacionais para a Formação de Professores da Educação Básica, em Cursos de Nível Superior. Disponível em: <http://portal.mec.gov.br/cne/arquivos/pdf/027.pdf>. Acesso em: 08 jul. 2013.

. Parecer $\mathrm{CNE} / \mathrm{CP} \mathrm{n}^{\circ} 28$, de 2 de outubro de 2001. Dá nova redação ao Parecer CNE/CP 21/2001, que estabelece a duração e a carga horária dos cursos de Formação de Professores da Educação Básica, em nível superior. Disponível em: $<$ http://portal.mec.gov.br/cne/arquivos/pdf/028.pdf > . Acesso em: 08 jul. 2013. 
BRASIL. Parecer CNE/CES $n^{0}$ 492, de 3 de abril de 2001. Diretrizes Curriculares Nacionais dos cursos de Filosofia, História, Geografia, Serviço Social, Comunicação Social, Ciências Sociais, Letras, Biblioteconomia, Arquivologia e Museologia. Disponível em: <http://portal.mec.gov.br/cne/ arquivos/pdf/CES0492.pdf>. Acesso em: 08 jul. 2013.

. Parecer CNE/CES n ${ }^{\circ} 1363$, de 12 de dezembro de 2001. Retifica o Parecer CNE/CES n. ${ }^{\circ} 492$, de 3 de abril de 2001, que aprova as Diretrizes Curriculares Nacionais dos cursos de Arquivologia, Biblioteconomia, Ciências Sociais - Antropologia, Ciência Política e Sociologia, Comunicação Social, Filosofia, Geografia, História, Letras, Museologia e Serviço Social. Disponível em: <http://portal.mec.gov.br/cne/arquivos/pdf/2001/pces1363_01.pdf>. Acesso em: 08 jul. 2013.

. Parecer CNE/CES no 68, de 9 de abril de 2008. Consulta sobre regularização de curso de Complementação Pedagógica em Administração Escolar, oferecido pelas Faculdades Integradas Maria Imaculada. Disponível em: <http://portal.mec.gov.br/cne/arquivos/pdf/2008/pces068_08.pdf > . Acesso em: 08 jul. 2013.

. Parecer CNE/CP n ${ }^{\circ} 5$, de 5 de maio de 2009. Consulta sobre a licenciatura em Espanhol por complementação de estudos. Disponível em: $<$ http://portal.mec.gov.br/index.php?option $=$ com_docman\&task $=$ doc_ download\&gid=7691\&Itemid=>. Acesso em: 08 jul. 2013.

. Secretaria de Educação Superior. Referenciais Curriculares Nacionais dos Cursos de Bacharelado e Licenciatura. Brasília, DF: Ministério da Educação, Secretaria de Educação Superior, 2010. Disponível em: <www.dca. ufrn.br/ adelardo/PAP/ReferenciaisGraduacao.pdf\$. Acesso em: 08 jul. 2013.

. Relatório Final. O que pensam os jovens de baixa renda sobre a escola. Brasília, DF: CEBRAP, 2013.

BUENO, B. O.; ENGE, J. S. Magistério e mercado de trabalho: motivações e dilemas na escolha profissional. Ensaio: Avaliação e Políticas Públicas em Educação, Rio de Janeiro, v. 12, n. 44, p. 789-809, jul./set. 2004.

FERNANDEZ, G. E.; RINALDI, S. Formação de professores de Espanhol para 
crianças no Brasil: alguns caminhos possíveis. Trab. linguist. apl., Campinas, v.48, n.2, p. 353-365, 2009.

GATTI, B. A. Atratividade da carreira docente no Brasil: Relatório Preliminar. São Paulo: Fundação Carlos Chagas, 2009.

GOMES, C. et al. Reforço escolar: gastos e desigualdades sociais. Revista Brasileira de Estudos Pedagógicos, Brasília, DF, v. 91, n. 227, p. 55-74, jan./ abr. 2010a.

. Sistema educativo sombra: recortes no Brasil e em Portugal. Revista Iberoamericana de Educación, Madri, n. 52/6, p. 1-14, maio $2010 \mathrm{~b}$.

GOUVEIA, A. J. Professôras de amanhã: um estudo de escolha ocupacional. 2. ed. São Paulo: Pioneira, 1970.

IMBERNÓN, F. Formação docente e profissional: formar-se para a mudança e a incerteza. 7. ed. São Paulo: Cortez, 2009.

IBGE. Instituto Brasileiro de Geografia E Estatística. Pesquisa Nacional por Amostra de Domicílios: Pesquisa básica - 2001 a 2012. Disponível em: $<$ http:// www.sidra.ibge.gov.br/bda/Tabela/protabl.asp?c $=262 \& \mathrm{z}=$ pnad $\& \mathrm{o}=3 \& \mathrm{i}=\mathrm{P}>$. Acesso em: 25 nov. 2013.

INEP. Instituto Nacional de Estudos e Pesquisas Educacionais Anísio Teixeira. Estudo exploratório sobre o professor brasileiro com base nos resultados do Censo Escolar da Educação Básica 2007. Brasília: Inep, 2009.

- Instituto Nacional de Estudos e Pesquisas Educacionais Anísio Teixeira. Microdados Censo Escolar 2012. Brasília: Inep, 2013. Disponível em: < http://portal.inep.gov.br/basica-levantamentos-acessar>. Acesso em: 10 ago. 2013.

LOURO, G. L. Mulheres na sala de aula. In: PRIORE, M. (Org.). História das Mulheres no Brasil. 10. ed. São Paulo: Contexto, 2011. p. 443-481.

MARTÍNEZ-CACHERO LASECA, Á. O ensino do espanhol no sistema 
educativo brasileiro. Brasília, DF: Thesaurus, 2008.

MIRANDA, M. H. G. de. Magistério masculino: (re) despertar tardio da docência. Recife: Ed. Universitária da UFPE, 2011.

PIMENTEL, G. S. R. O ensino médio no Brasil: busca recorrente de identidade e rupturas conceituais. 2013. 248f. Tese (Doutorado) Faculdade de EducaçãoUniversidade Católica de Brasília, Brasília,DF, 2013. Disponível em: $<\mathrm{http}: / /$ bdtd.ucb.br/tede/tde_busca/arquivo.php?codArquivo=1987>. Acesso em: 13 dez. 2013.

OCDE. ORGANIZAÇÃO PARA COOPERAÇÃO E DESENVOLVIMENTO ECONÔMICO. Professores são importantes: atraindo, desenvolvendo e retendo professores eficazes. São Paulo: Moderna, 2006.

OLIVEIRA, A. D. S. de. Os cursos de Pós-Graduação Lato Sensu em Educação Infantil na Bahia: políticas e práticas da universidade pública. 2012. 319f. Tese (Doutorado) - Faculdade de Educação, Universidade Federal de Goiás, Goiânia, 2012.

RUIZ, A. I. Sugestões para melhorar a educação básica: estudo comparativo entre a Espanha e o Brasil. São Paulo: Moderna, 2009.

SAMPAIO, M. M. F.; MARIN, A. J. Precarização do trabalho docente e seus efeitos sobre as práticas curriculares. Educação e Sociedade, Campinas, v. 25, n. 89 , p. 1203-1225, set./dez. 2004.

SOARES, T. M. Influência do professor e do ambiente em sala de aula sobre a proficiência alcançada pelos alunos avaliados no Simave-2002. Estudos em Avaliação Educacional, São Paulo, n. 28, jul./dez. 2003.

TARTUCE, G. L. B. P.; NUNES, M. M. R.; ALMEIDA, P, C. A. de. Alunos do ensino médio e atratividade da carreira docente no Brasil. Cadernos de Pesquisa, São Paulo, v. 40, n. 140, p. 445-477, maio/ago. 2010.

TEIXEIRA, A. Valores proclamados e valores reais nas instituições escolares 
brasileiras. Revista Brasileira de Estudos Pedagógicos, Brasília, DF, v.37, n.86, p. 59-79, abr./jun. 1962.

YOUNG, M. F. D. An approach to the study of curriculum as socially organized knowledge. In: YOUNG, M. F. D. (Org.). Knowledge and control: New directions for the sociology of education. Londres: Collier MacMillan, 1971. p. 19-46.

. Curriculum theory and the problem of knowledge: a personal journey and an unfinished project. MALEWSKI, E. (Org.). Curriculum studies handbook: the next moment. Nova Iorque: Routledge, 2010. p. 219-230.

\section{Not all that glitters is gold: a case of secondary education curricular change Abstract}

Brazilian secondary education curricula follows an historical encyclopedic tradition. However, new subjects have been added, according to central decisions, dependent on decentralized execution. One of them is these subjects is the Spanish language, based on geopolitical and geo-economic reasons. This paper analyses the preliminary results, including the teachers' profile. Evidences point out the high degree of improvisation, particularly employing a significant number of unprepared teachers. Almost a half of the schools declared not to offer that language. This change indicates that governmental decisions are subject to the bureaucracy's limits and to the political games, which may have as consequence their own de-legitimation.

Keywords: Teacher education. Educational policies. Secondary education. Spanish language.

\section{No es oro todo lo que reluce: un caso de cambio currricular en la enseñanza secundaria. Resumen}

La lengua española forma parte del plan de estudios de la educación secundaria por razones geopolíticas y geoeconómicas, según Ley $N^{\circ} 11.161$, del 5 de agosto de 2005. Este trabajo, desde la perspectiva sociológica del currículo, analiza la correspondiente legislación y normas, así como su práctica, inclusive el perfil 
del profesor, según los datos del Censo Escolar de 2012. Los resultados revelan un gran grado de improvisación, con la participación de elevado número de profesores sin cualificaciones adecuadas. Casi la mitad de las escuelas declaró no ofrecer la lengua española efectivamente. Estas constataciones Ilaman la atención para el plan de estudios de la educación secundaria, que se presenta fragmentado en numerosas asignaturas aisladas, tienen alto costo y complejidad, además de elevada selectividad sociocultural. Una de las consecuencias es la improvisación de profesores en asignaturas diferentes de aquellas para las cuales están preparados.

Palabras clave: Formación de profesores. Política educacional. Educación secundaria. Lengua española. 